\title{
Phenotypic and molecular characterization of Staphylococcus aureus isolates expressing low- and high-level mupirocin resistance in Nigeria and South Africa Adebayo O Shittu*1,3, Edet E Udo² and Johnson Lin ${ }^{3}$
}

\author{
Address: ${ }^{1}$ Department of Microbiology, Obafemi Awolowo University, Ile-Ife, Nigeria, ${ }^{2}$ Department of Microbiology, Faculty of Medicine, Kuwait \\ University, Kuwait City, Kuwait and ${ }^{3}$ School of Biochemistry, Genetics and Microbiology, University of KwaZulu-Natal (Westville Campus), \\ Private Bag X54001, Durban, Republic of South Africa \\ Email: Adebayo O Shittu* - bayo_shittu@yahoo.com; Edet E Udo - edete53@hotmail.com; Johnson Lin - linj@ukzn.ac.za \\ * Corresponding author
}

Published: 28 January 2009

BMC Infectious Diseases 2009, 9:10 doi:10.1186/1471-2334-9-10
Received: 28 May 2008

Accepted: 28 January 2009

This article is available from: http://www.biomedcentral.com/147/-2334/9/10

(C) 2009 Shittu et al; licensee BioMed Central Ltd.

This is an Open Access article distributed under the terms of the Creative Commons Attribution License (http://creativecommons.org/licenses/by/2.0), which permits unrestricted use, distribution, and reproduction in any medium, provided the original work is properly cited.

\begin{abstract}
Background: Mupirocin is a topical antimicrobial agent which is used for the treatment of skin and postoperative wound infections, and the prevention of nasal carriage of methicillin-resistant Staphylococcus aureus (MRSA). However, the prevalence of mupirocin resistance in S. aureus, particularly in MRSA, has increased with the extensive and widespread use of this agent in hospital settings. This study characterized low- and high-level mupirocin-resistant $S$. aureus isolates obtained from Nigeria and South Africa.
\end{abstract}

Methods: A total of 17 mupirocin-resistant S. aureus isolates obtained from two previous studies in Nigeria and South Africa, were characterized by antibiogram, PCR-RFLP of the coagulase gene and PFGE. High-level mupirocin resistant isolates were confirmed by PCR detection of the mupA gene. The genetic location of the resistance determinants was established by curing and transfer experiments.

Results: All the low-level mupirocin resistant isolates were MRSA and resistant to gentamicin, tetracycline and trimethoprim. PFGE identified a major clone in two health care institutions located in Durban and a health care facility in Pietermaritzburg, Greytown and Empangeni. Curing and transfer experiments indicated that high-level mupirocin resistance was located on a $4 \mathrm{l} . \mathrm{l} \mathrm{kb}$ plasmid in the South African strain (AI5). Furthermore, the transfer of high-level mupirocin resistance was demonstrated by the conjugative transfer of the $41.1 \mathrm{~kb}$ plasmid alone or with the co-transfer of a plasmid encoding resistance to cadmium. The size of the mupirocin-resistance encoding plasmid in the Nigerian strain (35 IBA) was approximately $35 \mathrm{~kb}$.

Conclusion: The emergence of mupirocin-resistant S. aureus isolates in Nigeria and South Africa should be of great concern to medical personnel in these countries. It is recommended that methicillin-susceptible $S$. aureus (MSSA) and MRSA should be routinely tested for mupirocin resistance even in facilities where the agent is not administered. Urgent measures, including judicious use of mupirocin, need to be taken to prevent clonal dissemination of the mupirocin/ methicillin resistant $S$. aureus in KZN, South Africa and the transfer of the conjugative plasmid encoding high-level mupirocin resistance identified in this study. 


\section{Background}

The treatment of infections caused by antibiotic-resistant bacteria especially methicillin-resistant Staphylococcus aureus (MRSA) has become a worldwide problem in hospital and community settings. Infection control programmes implement measures to contain the dissemination of MRSA which include efforts to eradicate carriage of $S$. aureus [1]. The antibiotic mupirocin used topically has been shown to possess potent activity against staphylococci and is used for the treatment of skin and postoperative wound infections, and the prevention of nasal carriage of MRSA [2,3]. However the widespread use of mupirocin led to resistance in $S$. aureus, which has been reported worldwide [4-9].

Mupirocin-resistant strains are divided into two groups: low- and high-level resistance (MIC 8-256 and >256 mg/ $\mathrm{L}$, respectively) [2]. In most cases, low-level resistance to mupirocin is related to alterations in the host isoleucyltRNA synthetase (IRS) [10,11]. Until recently, chromosomal mupirocin resistance was considered clinically unimportant $[2,12]$. However, low-level mupirocin resistance appears to be more prevalent in clinical isolates than high-level resistance [13-15], and the emergence of lowlevel mupirocin resistance has been shown to increase failure rates for nasal decolonization of MRSA [16-18]. High-level mupirocin resistant strains cannot be eradicated with mupirocin and constitute a serious clinical problem, especially when they are resistant to methicillin [19]. The clinical isolates exhibiting high-level resistance to mupirocin contain two distinct IRS enzymes: endogenous IRS plus an additional IRS encoded by the тирA gene [20], which is carried on plasmids that vary in size, restriction patterns and their ability to be transferred in conjugation experiments [4,20-23]. The mupA gene has also been reported in the genomic DNA of a few $S$. aureus isolates expressing low-level resistance, suggesting that the mupA gene may be located in the chromosome $[24,25]$. Moreover, the chromosomal location of the mupA gene in $S$. aureus expressing high-level mupirocin resistance has been described [26].

The previous studies conducted by these investigators indicated that the prevalence of $S$. aureus resistance to mupirocin in South Africa and Nigeria was 7\% and 0.5\% respectively $[7,27]$. This study reports on the phenotypic and molecular characterization of mupirocin-resistant $S$. aureus isolates in Nigeria and South Africa.

\section{Methods \\ Antimicrobial susceptibility testing and PCR detection of the mupA gene}

A total of 17 S. aureus isolates were investigated based on their resistance to mupirocin from two studies on antibiotic susceptibility patterns of $S$. aureus obtained from clin- ical samples in Nigeria and South Africa [7,27]. Susceptibility to various antibiotics was based on the disk diffusion method according to the National Committee for Clinical Laboratory Standards (now Clinical Laboratory Standards Institute) guidelines [28]. Susceptibility to heavy metals (cadmium acetate, mercuric chloride) and nucleic-acid binding compounds (ethidium bromide and propamidine isethionate) was performed on the isolates using disks prepared in the laboratory with the indicated concentrations $(10 \mu \mathrm{l})$ : cadmium acetate $(50 \mu \mathrm{g})$, propamidine isethionate $(50 \mu \mathrm{g})$, mercuric chloride, $(109 \mu \mathrm{g})$ and ethidium bromide $(60 \mu \mathrm{g})$. Interpretation of zone diameters were considered as follows: $\leq 9 \mathrm{~mm}$ (resistance), $10-12 \mathrm{~mm}$ (intermediate) for cadmium acetate; $\leq$ $25 \mathrm{~mm}$ (resistance) for mercuric chloride; $\leq 10 \mathrm{~mm}$ (resistance), 11-14 mm (intermediate) for propamidine isethionate; and $\leq 9 \mathrm{~mm}$ (resistance), $10-14 \mathrm{~mm}$ (intermediate) for ethidium bromide, as published previously [29]. Minimum inhibitory concentration (MIC) of mupirocin was determined using E-test strips ( $\mathrm{AB}$ Biodisk, Solna, Sweden) according to the manufacturer's instructions. The high-level mupirocin-resistant isolates (based on the disk diffusion and E-test methods) were confirmed by PCR detection of the mupA gene as described previously $[7,27]$.

The low-level mupirocin-resistant isolates were obtained from eleven wound samples and one isolate each from blood, urine samples, and endotracheal aspirate. Furthermore, the high-level mupirocin-resistant isolate (A15) from South Africa was obtained from a wound sample while 35 IBA, the isolate from Nigeria was recovered from a blood sample. Information on the source of the methicillin-susceptible $S$. aureus (MSSA) from South Africa (P1929) was not available.

\section{Plasmid DNA isolation}

Plasmid DNA was isolated by the cetyl trimethyl ammonium bromide method (CTAB) as earlier reported [30]. Plasmids were analysed by agarose $(0.6 \% \mathrm{w} / \mathrm{v})$ gel electrophoresis in $1 \times$ TAE buffer (pH 7.2) at $25 \mathrm{~V}$ for $16 \mathrm{hr}$. The Staphylococcus aureus strain WBG 4483, which has 4 plasmids $(40.3 \mathrm{~kb}, 22.5 \mathrm{~kb}, 4.4 \mathrm{~kb}$ and $3.5 \mathrm{~kb})$ served as the plasmid molecular size standard. The approximate plasmid sizes (closed circular forms) were estimated by visual inspection and using the GeneTools program (SynGene Bioimaging System, Cambridge, United Kingdom).

\section{Curing experiments}

Two of the three high-level mupirocin-resistant isolates (A15 - South Africa and 35 IBA - Nigeria) were selected for curing and conjugation experiments based on their antibiotic resistance profile. The mupirocin-resistant isolate P1929 from South Africa was not included in the experiment because its antibiotic susceptibility pattern 
was similar to 35 IBA. The loss of resistance determinants (plasmids) was investigated as previously reported [31]. The isolates were subcultured on Brain Heart Infusion Agar (BHIA, Biolab, South Africa) and incubated at $43.5^{\circ} \mathrm{C}$ for $24 \mathrm{hr}$. Sub-culturing on freshly prepared BHIA was performed twice and incubated as stated above. Thereafter, serial dilutions of the culture were plated on BHIA plates, and incubated at $37^{\circ} \mathrm{C}$ for 24 and 48 hrs. Single colonies were replica plated on BHIA plates as control and selection plates of BHIA containing mupirocin $(10 \mathrm{mg} / \mathrm{L})$ and erythromycin $(5 \mathrm{mg} / \mathrm{L})$ for A15, and mupirocin $(10 \mathrm{mg} / \mathrm{L})$ for 35 IBA. Single colonies which grew on the control plate but did not grow on the selection plates were noted and antibiotic susceptibility testing was performed on them to verify loss of resistance. Thereafter, colonies were screened for loss of the resistance determinants by plasmid analysis and visualized after electrophoresis on $0.6 \%$ agarose gels. Cured strains (susceptible to mupirocin) were confirmed for loss of resistance by a negative result for the mupA gene by PCR.

\section{Conjugation Experiments}

Conjugation experiments were performed in Brain Heart Infusion Broth (BHIB, Biolab, South Africa) with 40\% polyethylene glycol as previously reported [31]. Strains A15 and 35 IBA were used as donors and $S$. aureus WBG541 (fusidic and rifampicin-resistant) was the recipient strain. Donor and recipients controls were set up with each test. Transfer was considered to have occurred when growth was observed on the selection plates from the donor-recipient mixtures and not from the control experiments. The transconjugants (using A15 as the donor strain) were screened on BHIA plates containing mupirocin $(10 \mathrm{mg} / \mathrm{L})$, and fusidic acid $(5 \mathrm{mg} / \mathrm{L})$; erythromycin (5 mg/L) and fusidic acid (5 mg/L). Selections of transconjugants for 35 IBA were made on BHIA containing mupirocin $(10 \mathrm{mg} / \mathrm{L})$ and fusidic acid $(5 \mathrm{mg} / \mathrm{L})$; tetracycline $(5 \mathrm{mg} / \mathrm{L})$ and fusidic acid $(5 \mathrm{mg} / \mathrm{L})$. Transfer frequency was expressed as the number of transconjugants per number of donor cells. Single colonies of transconjugants were screened on BHIA containing appropriate antibiotics by the replica plating method and antibiotic susceptibility testing was performed on transconjugants. Furthermore, the transconjugants were screened to confirm plasmid content by agarose gel electrophoresis. In addition, transconjugants exhibiting highlevel resistance to mupirocin were confirmed by the MIC values and detection of the тирA gene.

\section{PCR-RFLP of the coagulase gene}

The 3' end region of the coagulase gene was amplified by PCR and restriction fragment polymorphisms (RFLPs) of the amplicons were determined by digestion with $A l u \mathrm{I}$ (Fermentas, UK) as previously described [7].

\section{PFGE typing}

PFGE typing of SmaI (Fermentas, UK) digested DNA was carried out by a modification of the protocol previously described [32]. The banding patterns were interpreted visually and strains showing the same PFGE pattern were classified into pulsotypes using an alphabet (e.g. A, B, C etc). Numeric sub-codes were used to represent $<3$ band difference (subtypes, e.g. A1, B1, etc) based on a previous report [33].

\section{Results}

Resistance pattern of low and high-level mupirocin resistant $S$. aureus isolates to antimicrobial agents

The resistance profiles of the mupirocin-resistant $S$. aureus isolates to various antimicrobial agents are presented in Table 1 . A total of 14 isolates from six health care institutions in KZN, South Africa exhibited low-level resistance to mupirocin (MIC: 8-24 mg/L). They were also resistant to methicillin, gentamicin, tetracycline and trimethoprim. A total of 12 low-level mupirocin resistant isolates were resistant to erythromycin, 10 isolates were resistant to ciprofloxacin, and four isolates each were resistant to rifampicin and chloramphenicol. Resistotyping revealed that six low-level mupirocin resistant isolates expressed resistance to cadmium acetate, propamidine isethionate, mercuric chloride and ethidium bromide. Four isolates were resistant only to mercuric chloride and two isolates were resistant to cadmium acetate and mercuric chloride. An MRSA isolate was susceptible to the heavy metals and nucleic-acid binding compounds. The тирA gene was not detected in the low-level mupirocin resistant strains while the high-level mupirocin resistant isolates with MIC of $>1024 \mathrm{mg} / \mathrm{L}$ tested positive for the mupA gene. Furthermore, the high-level mupirocin-resistant isolates were resistant to cadmium acetate but susceptible to mercuric chloride and nucleic acid binding compounds (Table 1).

\section{Genotyping (PCR-RFLP of the coagulase gene, PFGE) of low and high-level mupirocin resistant $S$. aureus strains}

Molecular typing by PCR-RFLP of the coagulase gene identified three RFLP patterns in the low- $(81 \mathrm{bp}, 567 \mathrm{bp}$; $325 \mathrm{bp}, 405 \mathrm{bp}$ and $81 \mathrm{bp}, 324 \mathrm{bp}, 405 \mathrm{bp}$ ) and high-level (81 bp, 567 bp; 243 bp, 486 bp and 81 bp, 162 bp, 567 bp) mupirocin-resistant strains (Figure 1). PFGE identified two pulsotypes (A and B) among the low-level mupirocin-resistant $S$. aureus strains, and 10 of 14 strains $(71.4 \%)$ were classified in type A (Figure 2 ). The strains in type A were observed in two health care institutions located in Durban and a health care facility in Pietermaritzburg, Greytown and Empangeni, while type B was noted in two health care institutions in Durban and in Eshowe. Based on their PFGE patterns, the high-level mupirocin-resistant strains from the two countries were unrelated (Figure 3). 
Table I: Characterization (antibiogram, PCR-RFLP of the coagulase gene and PFGE) of low and high-level mupirocin resistant S. aureus isolated in Nigeria and South Africa

\begin{tabular}{|c|c|c|c|c|c|c|}
\hline Strain No & $\begin{array}{l}\text { Antibacterial } \\
\text { resistance patterns }\end{array}$ & $\begin{array}{l}\text { MUPMIC } \\
(\mathrm{mg} / \mathrm{L})\end{array}$ & $\begin{array}{l}\text { mupA } \\
\text { gene }\end{array}$ & $\begin{array}{l}\text { Coagulase gene } \\
\quad( \pm 20 \text { bp })\end{array}$ & $\begin{array}{l}\text { PCR-RFLP } \\
\text { Coagulase } \\
\text { gene (bp) }\end{array}$ & $\begin{array}{l}\text { PFGE } \\
\text { type }\end{array}$ \\
\hline Al & PEN, OX, GN, ERY, CHL, TET, TS, CIP, MU (L), Hg & 12 & - & 800 & 324,405 & A \\
\hline A2 & PEN, OX, GN, TET, TS, RF, MU (L) & 24 & - & 650 & 81,567 & B \\
\hline A3 & PEN, OX, GN, ERY, TET, TS, CIP, MU (L), Cad, Pi, Hg, Eb & 16 & - & 850 & 324,405 & A \\
\hline A4 & PEN, OX, GN, TET, TS, RF, MU (L), Cad, Hg & 24 & - & 650 & 81,567 & B \\
\hline A5 & PEN, OX, GN, ERY, CHL, TET, TS, CIP, MU (L), Cad, Pi, Hg, Eb & 12 & - & 800 & 324,405 & $\mathrm{Al}$ \\
\hline A6 & PEN, OX, GN, ERY, TET, TS, CIP, MU (L), Cad, Pi, Hg, Eb & 8 & - & 800 & $81,324,405$ & A \\
\hline A7 & PEN, OX, GN, ERY, TET, TS, RF, MU (L), Cad & 24 & - & 650 & 81,567 & $\mathrm{BI}$ \\
\hline A8 & PEN, OX, GN, ERY, CHL, TET, TS, CIP, MU (L), Cad, Pi, Hg, Eb & 8 & - & 800 & $81,324,405$ & A \\
\hline A9 & PEN, OX, GN, ERY, TET, TS, RF, MU (L), Cad, Hg & 24 & - & 650 & 81,567 & B2 \\
\hline Al0 & PEN, OX, GN, ERY, CHL, TET, TS, CIP, MU (L), Hg & 12 & - & 800 & $81,324,405$ & A \\
\hline All & PEN, OX, GN, ERY, TET, TS, CIP, MU (L), Cad, Pi, Hg, Eb & 8 & - & 800 & $81,324,405$ & A \\
\hline $\mathrm{A} 12$ & PEN, OX, GN, ERY, TET, TS, CIP, MU (L), Hg & 12 & - & 850 & $81,324,405$ & $\mathrm{~A} 2$ \\
\hline $\mathrm{A} 13$ & PEN, OX, GN, ERY, TET, TS, CIP, MU (L), Hg & 8 & - & 800 & $81,324,405$ & $\mathrm{Al}$ \\
\hline Al4 & PEN, OX, GN, ERY, TET, TS, CIP, MU (L), Cad, Pi, Hg, Eb & 12 & - & 800 & $81,324,405$ & A \\
\hline Al5 & PEN, OX, GN, ERY, TET, TS, RF, MU (H), Cad & $>1024$ & + & 650 & 81,567 & B3 \\
\hline PI929 & TM, TET, MU (H), Cad & $>1024$ & + & 750 & 243,486 & C \\
\hline $35 \mathrm{IBA}$ & TET, MU $(\mathrm{H})$, Cad & $>1024$ & + & 800 & $81,162,567$ & $\mathrm{D}$ \\
\hline
\end{tabular}

KEY. PEN - Penicillin, OX - Oxacillin, GN - Gentamicin, ERY - Erythromycin, CHL - Chloramphenicol,

TET - Tetracycline, TS - Trimethoprim, RF - Rifamipicin, CIP - Ciprofloxacin,

MU $(H)$ - High-level mupirocin resistance, MU $(L)$ - Low-level mupirocin resistance

Heavy metals - Cad: Cadmium acetate; Hg: Mercuric chloride Nucleic acid binding compounds - Eb: Ethidium bromide; Pi: Propamidine isethionate

\section{Curing experiment}

The isolates 35 IBA and A15 expressing high-level mupirocin resistance were subjected to curing experiments as a first step to determining the genetic location of their resistance determinants. Results of the curing experiments with 35 IBA showed that 6 of 293 colonies $(2.0 \%)$ screened for loss of resistance were susceptible to mupirocin. Agarose gel electrophoresis indicated that this was associated with the loss of $c .35 \mathrm{~kb}$ plasmid (Figure 4). Of the 294 colonies screened on mupirocin and erythromycin selection plates for A15, three and six colonies lost resistance to erythromycin and mupirocin respectively. Resistance to these antibiotics in the cured strains was lost together with plasmids of $c .2 .3 \mathrm{~kb}$ and $38 \mathrm{~kb}$ respectively (Figure 4). The mupA gene was not detected in the cured strains (susceptible to mupirocin) by PCR.

\section{Conjugation experiment}

Transconjugants were not observed on mupirocin selection plates when 35 IBA was used as the donor strain. However, transconjugants were obtained on mupirocin selection plates with A15 as the donor strain. Replica plating of 98 transconjugants on BHIA selection plates with cadmium (5 mg/L), erythromycin (5 mg/L) and mupirocin $(10 \mathrm{mg} / \mathrm{L})$ yielded one, three and 98 colonies respectively. The susceptibility pattern of the parent and cured 


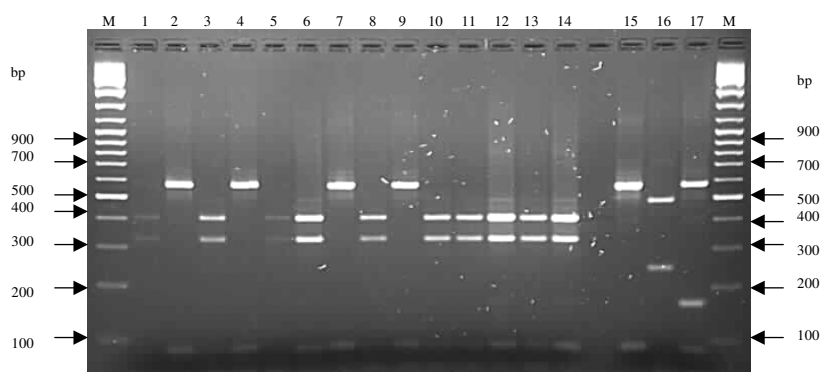

Figure I

PCR-RFLP of the coagulase gene in mupirocin-resistant strains. M: Molecular weight marker (I00 bp). Lanes I14: Low-level mupirocin resistant strains: AI-AI4. Lanes I517: High-level mupirocin-resistant strains: AI5, PI929 (South Africa), 35 IBA (Nigeria).

strains along with the transconjugants are presented in Table 2 . The transfer frequency was calculated as $1.2 \times 10^{-}$ 5 and $2 \times 10^{-8}$ for mupirocin and erythromycin resistance determinants respectively. Transconjugants that were resistant to mupirocin contained a single plasmid of $c .38$ $\mathrm{kb}$ while those resistant to mupirocin and cadmium carried two plasmids of $c .38 \mathrm{~kb}$ and $25 \mathrm{~kb}$ in size (Figure 5). EcoRI restriction analysis showed that the plasmid in the mupirocin-resistant transconjugant (TransMup) yielded seven fragments $(12.6,10.9,6.3,4.8,2.5,2.3$ and $1.7 \mathrm{~kb})$ indicating that the size of the mupirocin plasmid was 41.1 $\mathrm{kb}$ (Figure 6). The two plasmids in mupirocin and cadmium-resistant transconjugant (TransCad) produced nine EcoRI fragments $(17.3,12.6,10.9,6.3,4.8,2.7,2.5,2.3$, $1.7 \mathrm{~kb}$ ) with seven fragments identical to those of the 41.1

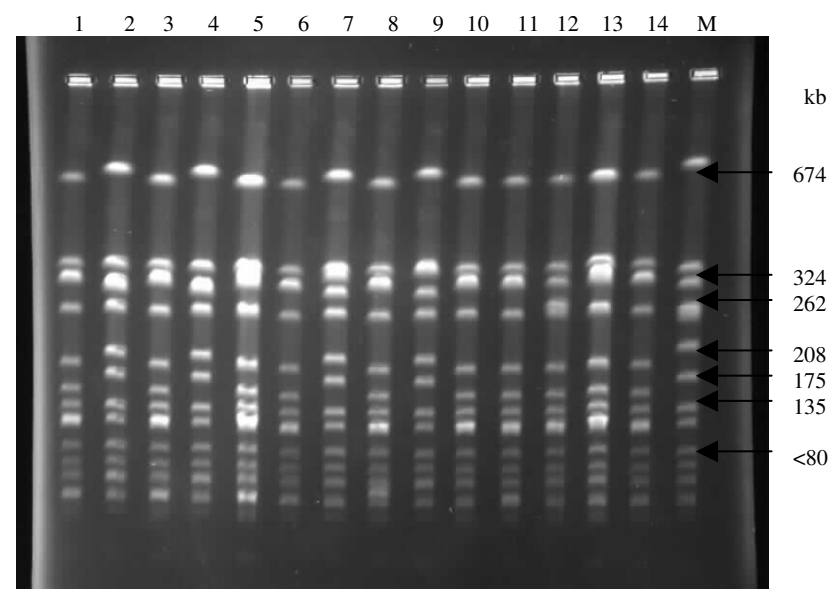

$\begin{array}{lllllllllllllllllllllll}\text { A } & \text { B } & \text { A } & \text { B } & \text { A1 } & \text { A } & \text { B1 } & \text { A } & \text { B2 } & \text { A } & \text { A } & \text { A2 } & \text { A1 } & \text { A }\end{array}$

Figure 2

PFGE patterns of low-level mupirocin-resistant strains. M: Molecular weight standard S. aureus NCTC 8325. Lanes I-|4: AI-AI4.

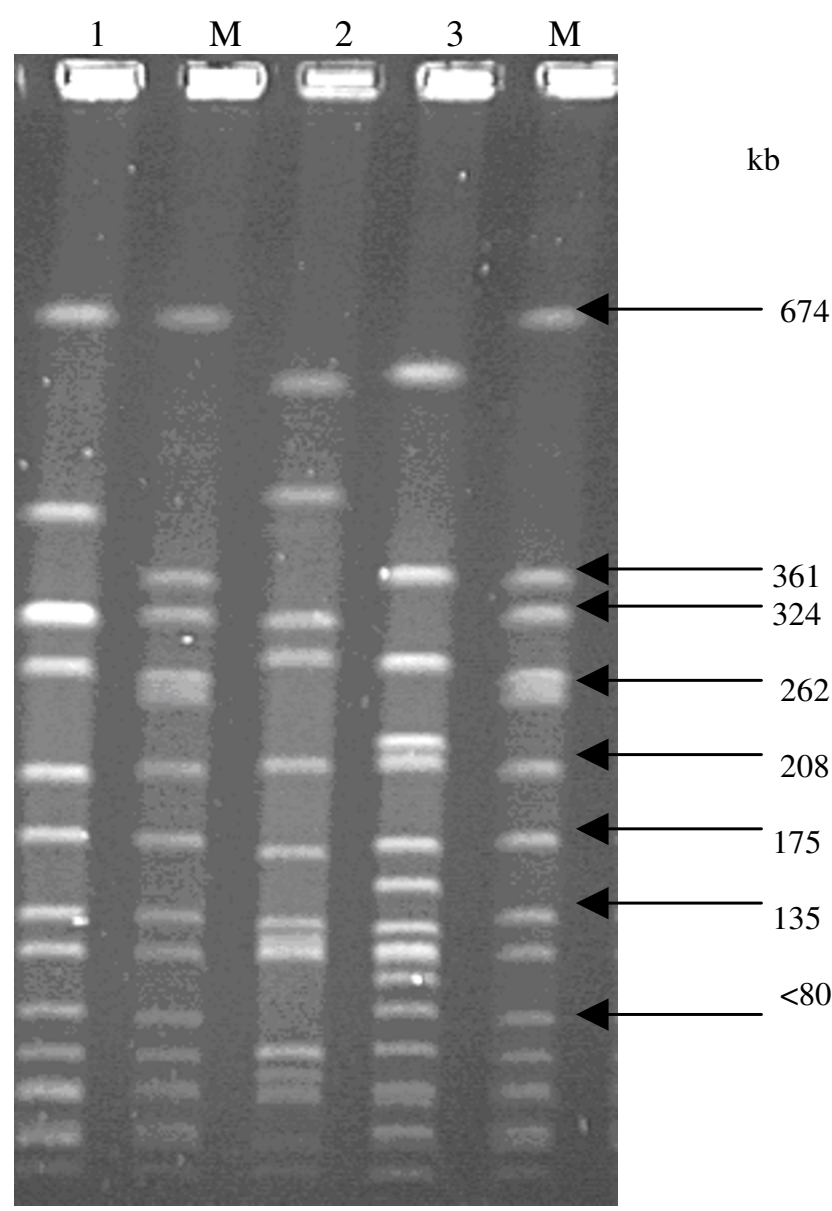

B3 C D

Figure 3

PFGE patterns of high-level mupirocin-resistant strains from Nigeria and South Africa. M: Molecular weight standard S. aureus NCTC 8325; Lane I: AI5; Lane 2: PI929; Lane 3: 35 IBA

kb plasmid in TransMup. The additional 17.3 and $2.7 \mathrm{~kb}$ $(20 \mathrm{~kb})$ fragments were associated with the second plasmid carrying cadmium resistance in TransCad (Figure 6).

\section{Discussion}

This investigation studied mupirocin-resistant $S$. aureus that were isolated in Nigeria and South Africa, using phenotypic and molecular methods. Clinical isolates of mupirocin-resistant S. aureus was first reported in 1987 [34], and resistance has frequently been attributed to the clinical use of mupirocin over extended periods [23] or in areas of highly concentrated application, such as dermatology or burns units $[35,36]$. Mupirocin is prescribed and administered for the treatment of MRSA infections and $S$. aureus nasal colonization among hospital patients in 


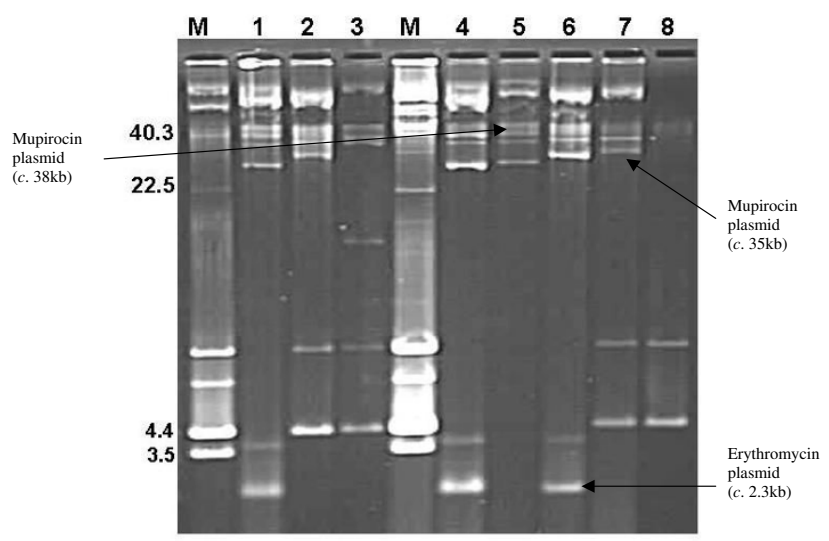

\section{Figure 4}

Plasmid profiles of parent and cured strains: $M$ : Molecular weight marker (WBG 4483; Only closed circular DNA are labelled); Lanes I-3: High-level mupirocin-resistant strains: Lane I - AI5 (South Africa), Lane 2 - 35 IBA (Nigeria), Lane 3 - PI 929 (South Africa); Lane 4: AI 5 parent strain; Lane 5 - AI 5'A (cured strain of AI5 - resistant to mupirocin, susceptible to erythromycin $-38 \mathrm{~kb}$ plasmid encoding high-level mupirocin resistance); Lane $6-A I 5^{C} D$ (cured strain of AI5 - susceptible to mupirocin, resistant to erythromycin - $2.3 \mathrm{~kb}$ plasmid); Lane 7 - 35 IBA parent (35 kb plasmid encoding high-level mupirocin resistance); Lane 8 - 35 IBA (CUR) - cured strain of 35 IBA (susceptible to mupirocin, resistant to tetracycline).

$\mathrm{KZN}$, and it appears that the extensive use of the agent in health care institutions has contributed to the emerging trend of $S$. aureus resistance. Typing based on phenotypic and genotypic methods play an important role in understanding the epidemiology of MRSA and evaluating the effectiveness of infection control and antimicrobial prescribing measures [37]. In this study, two main PFGE types (A and B) were identified among the low-level mupirocin resistant strains obtained from six health care institutions in the KZN province of South Africa. The strains in pulsotype A were identified in two health care institutions located in Durban and a health care facility in Pietermaritzburg, Greytown and Empangeni, while pulsotype B was noted in two health care institutions in Durban and in Eshowe. Some degree of correlation was observed with the three typing methods. The low-level mupirocinresistant strains with a PCR-RFLP pattern of 81, 567 bp belonged to the clone B by PFGE typing. Moreover, MRSA strains with PCR-RFLP pattern of $81,324,405$ bp and 324,405 bp had similar antibiotic resistance pattern and belonged to the dominant clone A. Hence, this study has demonstrated clonal dissemination of multiresistant MRSA strains exhibiting low-level resistance to mupirocin in health institutions in KZN province of South Africa. The emergence and spread of low-level mupirocin-resistant $S$. aureus should be of concern among health care

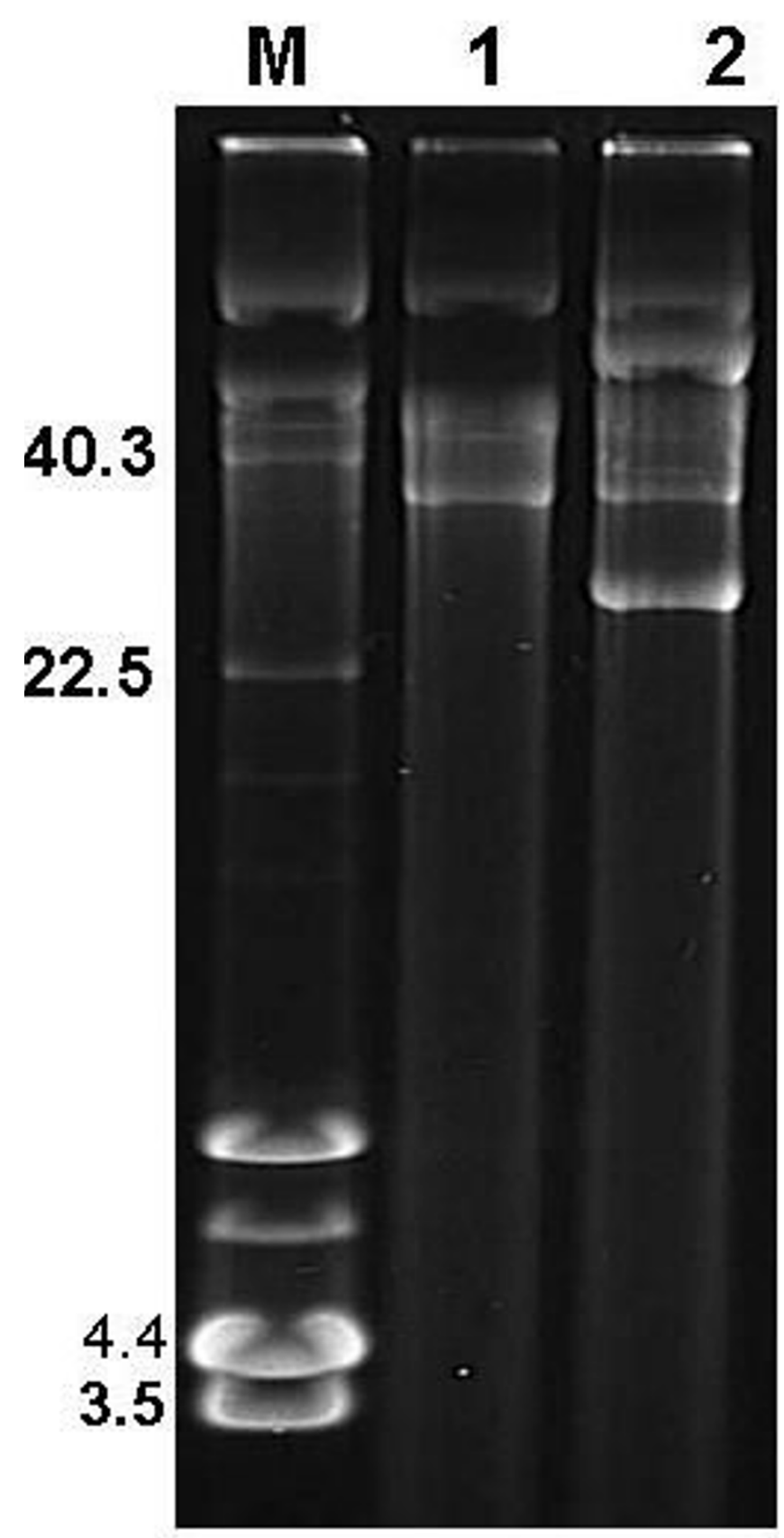

Figure 5

Plasmid profile of transconjugants derived from the methicillin/mupirocin resistant S. aureus (strain A I 5) from South Africa. M - WBG 4483 (only the closed circular forms of the plasmids are labelled); Lane I - TransMup (resistant to mupirocin); Lane 2 - TransCad (resistant to mupirocin and cadmium).

workers in South Africa because of recent reports on the increase in treatment failure rates for nasal decolonization of MRSA due to the emergence of low-level mupirocin resistance [16-18]. 


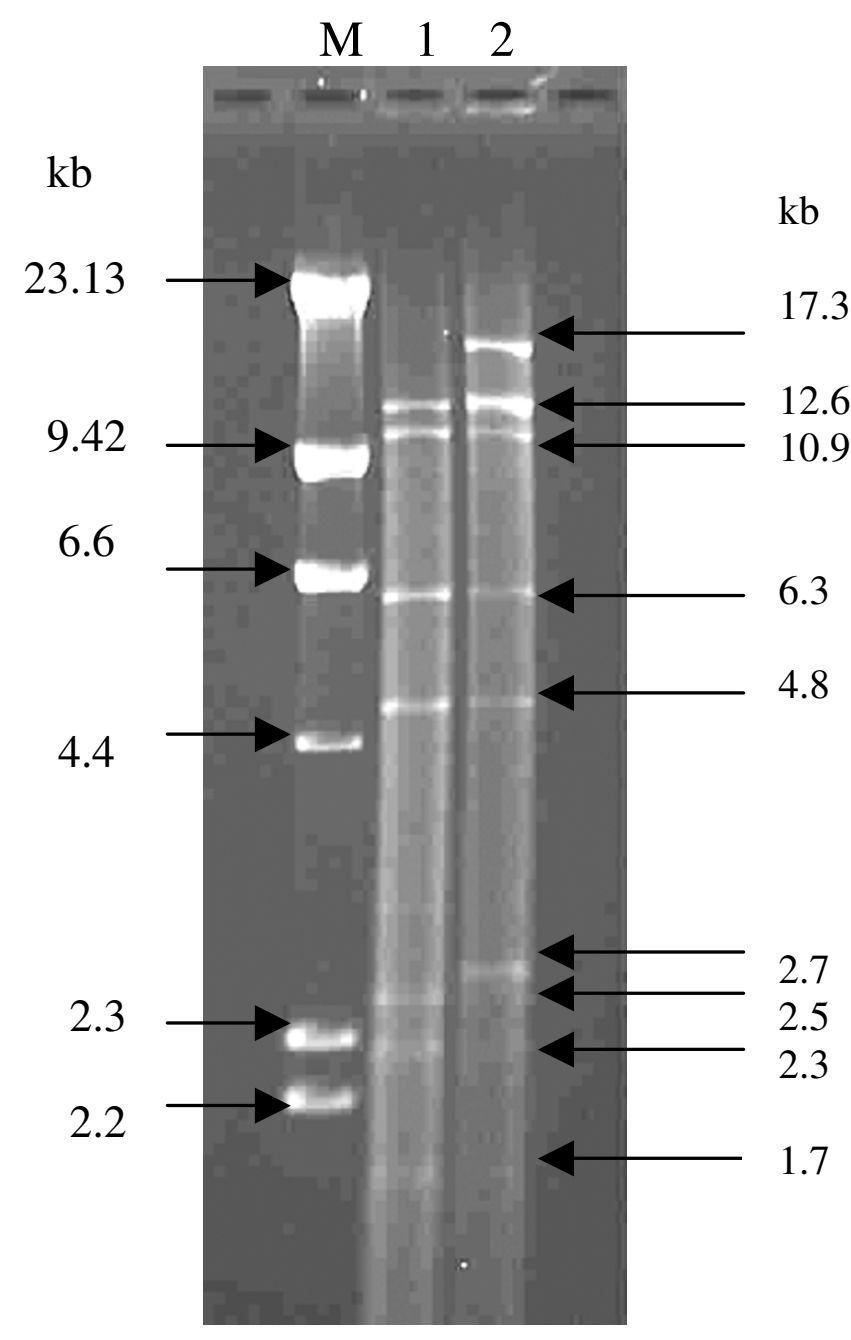

Figure 6

EcoRI restriction pattern (plasmids) of transconjugants derived from the methicillin/mupirocin resistant S. aureus (AI5) strain from South Africa. M:

Molecular weight standard, phage lambda DNA digested with HindIII; Lane I - TransMup (resistant to mupirocin); Lane 2 TransCad (resistant to mupirocin and cadmium).

Plasmid-mediated resistance to antimicrobial agents among pathogenic bacteria constitutes a major clinical and economic problem worldwide. In this study, the genetic location of the high-level mupirocin resistance determinant was resolved in two isolates by plasmid analysis, involving curing and conjugation experiments. Three features were identified in the transfer experiments and plasmid analysis. The first feature was the transfer of the $41.1 \mathrm{~kb}$ plasmid encoding high-level mupirocin resistance. High-level mupirocin resistance has been found in self-transmissible and non-self transmissible plasmids in different countries [4,38-40], and this study has demonstrated what appears to be the first report of a conjugative mupirocin resistance plasmid in South Africa. The conjugative transfer of plasmids mediating high-level mupirocin resistance may involve the co-transfer of small nonconjugative plasmids encoding resistance to tetracycline and chloramphenicol [22,23,40,41] and large plasmids encoding resistance to penicillin [42]. The transfer of resistance determinants mediating mupirocin and triclosan resistance in MRSA has also been reported [43]. The second feature was the conjugative transfer of a 41.1 $\mathrm{kb}$ plasmid mediating mupirocin resistance along with the co-transfer of a plasmid encoding resistance to cadmium (Table 2; Figure 5). This observation suggests that the $41.1 \mathrm{~kb}$ plasmid belong to a class of conjugative plasmids that could be co-transferred with other resistance determinants. The third feature was the transfer of a $2.3 \mathrm{~kb}$ plasmid mediating erythromycin resistance. Although our observations on plasmid analysis and conjugation experiments are preliminary due to the number of isolates studied, the demonstration of conjugative transfer of the mupirocin resistance plasmid and its co-transfer with other resistance plasmids clearly supports the judicious use of this topical antibiotic in health institutions in South Africa. Hence, urgent measures need to be taken to prevent clonal dissemination of the mupirocin/methicillin resistant $S$. aureus in KZN, South Africa. Future work include investigating the nature of the plasmid encoding mupirocin resistance in 35 IBA and P1929, the full sequence and comparison of the mupA gene with other sequences in the GenBank. This could probably provide new insights on the evolution of the mupA gene in $S$. aureus.

\section{Conclusion}

This study has demonstrated the clonal dissemination of multi-resistant MRSA strains exhibiting low-level resistance to mupirocin in KZN and the emergence of highlevel mupirocin resistant $S$. aureus in Nigeria and South Africa. Although the high-level mupirocin resistant $S$. aureus strains from the two countries are genetically unrelated, the ability of the $41.1 \mathrm{~kb}$ mupirocin plasmid to transfer the resistance determinant indicate the potential for spread to mupirocin-susceptible MSSA and MRSA isolates under the selective pressure of mupirocin. It is also recommended that routine testing of MSSA and MRSA for mupirocin resistance be conducted even in facilities where mupirocin is not administered. This will facilitate the early detection of resistance and assist in the control and spread of mupirocin-resistant $S$. aureus.

\section{Competing interests}

The authors declare that they have no competing interests.

\section{Authors' contributions}

AOS participated in the collection, susceptibility pattern and characterization of the mupirocin-resistant isolates. 
Table 2: Susceptibility profile of parent, cured, recipient strains and transconjugants derived from strain AI 5

\begin{tabular}{|c|c|c|c|}
\hline Strain & Resistance pattern & MUP MIC (mg/L) & mupA gene \\
\hline 35 IBA (parent) & TET, MU (H) & $>1024$ & + \\
\hline 35 IBA (CUR) - cured strain & TET & 0.064 & - \\
\hline AI5 (parent) & OX, ERY, CDRi, RF, TET, MU (H) & $>1024$ & + \\
\hline$A \mid 5^{c} A$ (cured strain of $A \mid 5$ ) & OX, RF, TET, MU (H) & $>1024$ & + \\
\hline$A \mid 5^{\circ} D($ cured strain of $A \mid 5)$ & OX, ERY, CDRi, RF & 0.0125 & - \\
\hline WBG 54I (recipient strain) & RF, FC & ND & - \\
\hline TransEry (transconjugant of AI5) & RF, FC, ERY, CDRi & ND & - \\
\hline TransMup (transconjugant of AI5) & RF, FC, MU (H) & $>1024$ & + \\
\hline TransCad (transconjugant of AI5) & RF, FC, MU (H), Cad & $>1024$ & + \\
\hline
\end{tabular}

TET - Tetracycline; MU (H) - High-level mupirocin resistance; OX - Oxacillin;

ERY - Erythromycin; CDRi - Clindamycin (inducible resistance); RF - Rifampicin;

FC - Fusidic acid; Cad - Cadmium; ND - Not determined

EEU planned the plasmid analysis and JL supervised the project. All authors participated in the preparation of the final manuscript.

\section{Acknowledgements}

We would like to thank the management of the hospitals and Professor S. Essack, Faculty of Pharmacy, University of KwaZulu-Natal, for their support in the collection of the isolates. We also thank Drs. Oliver Preisig and Iruka Okeke for their comments in the preparation of this manuscript. The assistance of the Department of Microbiology, Faculty of Medicine, Kuwait, and Mrs. Bindu Matthew during the research visit of AOS is appreciated. The National Research Foundation, Republic of South Africa, supported the study.

\section{References}

I. Girou E, Pujade G, Legrand P, Cizeau F, Brun-Buisson C: Selective screening of carriers for control of methicillin-resistant Staphylococcus aureus (MRSA) in high-risk hospital areas with a high level of endemic MRSA. Clin Infect Dis 1998, 27:543-550.

2. Cookson BD: The emergence of mupirocin-resistance: a challenge to infection control and antibiotic prescribing practice. J Antimicrob Chemother 1998, 4 I: I I- I8.

3. Herwaldt LA: Reduction of Staphylococcus aureus nasal carriage and infection in dialysis patients. J Hosp Infect 1998:SI3-S23.

4. Udo EE, Pearman JW, Grubb WB: Emergence of high-level mupirocin resistance in methicillin-resistant Staphylococcus aureus in Western Australia. J Hosp Infect 1994, 26: 157-I65.

5. Caierao J, Berquo L, Dias C, d'Azevedo PA: Decrease in the incidence of mupirocin resistance among methicillin-resistant Staphylococcus aureus in carriers from an intensive care unit. Am J Infect Control 2006, 34:6-9.

6. Gadepalli R, Dhawan B, Mohanty S, Kapil A, Das BK, Chaudhry R, Samantaray JC: Mupirocin resistance in Staphylococcus aureus in an Indian hospital. Diagn Microbiol Infect Dis 2007, 58:125-127.

7. Shittu $A O$, Lin J: Antimicrobial susceptibility patterns and characterization of clinical isolates of Staphylococcus aureus in KwaZulu-Natal province, South Africa. BMC Infect Dis 2006, 6(I): 125 .
8. Aucken HM, O'Neill G, Ganner M, Dinerstein N, Ali M, Murchan S: Irish-I and Irish-2: UK epidemic methicillin-resistant Staphylococcus aureus strains associated with Northern Ireland. Hosp Infect 2006, 63: 170-178.

9. Jones PG, Sura T, Harris M, Strother A: Mupirocin resistance in clinical isolates of Staphylococcus aureus. Infect Control Hosp Epidemiol 2003, 24:301-302.

10. Farmer TH, Gilbart J, Elson SW: Biochemical basis of mupirocin resistance in strains of Staphylococcus aureus. J Antimicrob Chemother 1992, 30:587-596.

II. Antonio M, McFerran N, Pallen M: Mutations affecting the Rossman fold of isoleucyl-tRNA synthestase are correlated with low-level mupirocin resistance in Staphylococcus aureus. Antimicrob Agents Chemother 2002, 46:438-442.

12. Henkel T, Finlay J: Emergence of resistance during mupirocin treatment: is it a problem in clinical practice? J Chemother 1999, II:331-337.

13. Schmitz F], Lindenlauf E, Hofmann B, Fluit AC, Verhoef J, Heinz HP, Jones ME: The prevalence of low- and high-level mupirocin resistance in staphylococci from 19 European hospitals. Antimicrob Chemother 1998, 42:489-495.

14. Deshpande LM, Fix AM, Pfaller MA, The SENTRY Antimicrobial Surveillance Program Participants Group, Jones RN: Emerging elevated mupirocin resistance rates among staphylococcal isolates in the SENTRY Antimicrobial Surveillance Program (2000): correlations of results from disk diffusion, E-test and reference dilution methods. Diagn Microbiol Infect Dis 2002, 42:283-290.

15. Fujimura $S$, Watanabe A: Survey of high- and low-level mupirocin-resistant strains of methicillin-resistant Staphylococcus aureus in Japanese hospitals. Chemother 2003, 49:36-38.

16. Harbath S, Liassine N, Dharan S, Herrault P, Auckenthaler R, Pittet D: Risk factors for persistent carriage of methicillin-resistant Staphylococcus aureus. Clin Infect Dis 2000, 31:1380-1385.

17. Watanabe H, Masaki H, Asoh N, Watanabe K, Oishi K, Furumoto A, Kobayashi S, Sato A, Nagatake T: Emergence and spread of lowlevel mupirocin resistance in methicillin-resistant Staphylococcus aureus isolated from a community hospital in Japan. J Hosp Infect 200I, 47:294-300.

18. Decousser JW, Pina P, Ghnassia JC, Bedos JP, Allouch PY: First report of clinical and microbiological failure in the eradication of glycopeptide-intermediate methicillin-resistant Sta- 
phylococcus aureus carriage by mupirocin. Eur J Clin Microbiol Infect Dis 2003, 22:318-319.

19. Perez-Roth E, Claverie-Martin F, Moreno A, Mendez-Alvarez S: Mupirocin resistance in methicillin-resistant Staphylococcus aureus clinical isolates in a Spanish hospital. Co-application of multiplex PCR assay and conventional microbiology methods. Diagn Microbiol Infect Dis 2002, 43:123-128.

20. Morton TM, Johnston JL, Patterson J, Archer GL: Characterization of a conjugative staphylococcal mupirocin resistance plasmid. Antimicrob Agents Chemother 1995, 39: I272-1 280.

21. Rahman M, Conolly S, Noble WC, Cookson B, Phillips I: Diversity of staphylococci exhibiting high-level resistance to mupirocin. J Med Microbiol 1990, 33:97-100.

22. Needham C, Rahman M, Dyke KGH, Noble WC: An investigation of plasmids from Staphylococcus aureus that mediate resistance to mupirocin and tetracycline. Microbiology 1994, I 40:2577-2583.

23. Udo EE, Jacob LE: Conjugative transfer of high-level mupirocin resistance and the mobilization of non-conjugative plasmids in Staphylococcus aureus. Microb Drug Resist 1998, 4:185-193.

24. Ramsey MA, Bradley SF, Kaufmann CA, Morton TM: Identification of chromosomal location of mupA gene encoding low-leve mupirocin resistance in staphylococcal isolates. Antimicrob Agents Chemother 1996, 40:2820-2823.

25. Fujimura $S$, Watanabe A, Beighton D: Characterization of the mupA gene in strains of methicillin-resistant Staphylococcus aureus with low level of resistance to mupirocin. Antimicrob Agents Chemother 200I, 45:64I-642.

26. Udo EE, Al-Sweih N, Noronha BC: A chromosomal location of the mupA gene in Staphylococcus aureus expressing high-level mupirocin resistance. J Antimicrob Chemother 2003, 5 I: I 283- 1286.

27. Shittu AO, Lin J, Kolawole DO: Antimicrobial susceptibility patterns of Staphylococcus aureus and characterization of MRSA in Southwestern Nigeria. WOUNDS 2006, 18:77-84.

28. National Committee for Clinical Laboratory Standards (now Clinical Laboratory Standards Institute): Performance standards for antimicrobial disk susceptibility tests. NCCLS document M2-A8 Wayne, PA-NCCLS 2003.

29. Emslie KR, Townsend DE, Grubb WB: A resistance determinant to nucleic acid binding compounds in methicillin-resistant Staphylococcus aureus. J Med Microbiol 1985, 20:139-145.

30. Townsend DE, Ashdown N, Bolton S, Grubb WB: The use of cetyltrimethylammonium bromide for the rapid isolation from Staphylococcus aureus of relaxable plasmid DNA for in vitro manipulation. Letts Appl Microbiol 1985, I:87-94.

31. Townsend DE, Bolton S, Ashdown N, Grubb WB: Transfer of plasmid-borne aminoglycoside resistance determinants in staphylococci. J Med Microbiol 1985, 20:|69-| 85.

32. Bannerman TL, Hancock GA, Tenover FC, Miller JM: Pulsed-field gel electrophoresis as a replacement for bacteriophage typing of Staphylococcus aureus. J Clin Microbiol I995, 33:55I-555.

33. Tenover FC, Arbeit RD, Goering RV, Mickelsen PA, Murray BE, Persing $\mathrm{DH}$, Swaminathan B: Interpreting chromosomal DNA restriction patterns produced by pulsed-field gel electrophoresis: criteria for bacterial strain typing. J Clin Microbiol 1995, 33:2233-2239.

34. Rahman M, Noble WC, Cookson BD: Mupirocin-resistant Staphylococcus aureus. Lancet 1987, ii:387.

35. Eltringham I: Mupirocin resistance and methicillin-resistant Staphylococcus aureus (MRSA). J Hosp Infect 1997, 35: I-8.

36. Poupard JA: Update on mupirocin resistance. J Chemother 1995, 7 Suppl 3:7I-74.

37. Murchan S, Kaufmann ME, Deplano A, de Ryck R, Struelens M, Zinn CE, Fussing V, Salmenlinna S, Vuopio-Varkila J, El Solh N, Cuny C, Witte W, Tassios PT, Legakis N, van Leeuwen W, van Belkum A, Vindel A, Laconcha I, Garaizar J, Coombs G, Cookson B: Harmonization of pulsed-field gel electrophoresis for epidemiological typing of methicillin-resistant Staphylococcus aureus: a single approach developed by consensus in 10 European centers and its application for tracing the spread of related strains. J Clin Microbiol 2003, 4 I: I 574-I585.

38. Rahman M, Noble WC, Cookson BD: Transmissible mupirocin resistance in Staphylococcus aureus. Epidemiol Infect 1989, 102:261-270.

39. Connolly S, Noble WC, Phillips I: Mupirocin resistance in coagulase-negative staphylococci. J Med Microbiol 1993, 39:450-453.
40. Udo EE, Jacob LE, Mokaddas EM: Conjugative transfer of highlevel mupirocin resistance from Staphylococcus haemolyticus to other staphylococci. Antimicrob Agents Chemother 1997, 41:693-695.

4I. Udo EE, Jacob LE, Mathew B: The spread of a mupirocin-resistant/methicillin-resistant Staphylococcus aureus clone in Kuwait hospitals. Acta Trop 200I, 81:155-161.

42. Pawa A, Noble WC, Howell SA: Co-transfer of plasmids in association with conjugative transfer of mupirocin or mupirocin and penicillin resistance in methicillin-resistant Staphylococcus aureus. J Med Microbiol 2000, 49: I I03-II 07.

43. Cookson BD, Farelly H, Stapleton P, Gravey RPJ, Price MR: Transferable resistance to triclosan in MRSA. Lancet |99|, 337:1548-1549.

\section{Pre-publication history}

The pre-publication history for this paper can be accessed here:

http://www.biomedcentral.com/1471-2334/9/10/prepub
Publish with Biomed Central and every scientist can read your work free of charge

"BioMed Central will be the most significant development for disseminating the results of biomedical research in our lifetime. "

Sir Paul Nurse, Cancer Research UK

Your research papers will be:

- available free of charge to the entire biomedical community

- peer reviewed and published immediately upon acceptance

- cited in PubMed and archived on PubMed Central

- yours - you keep the copyright 